\title{
Crunch time for the Clean Development Mechanism?
}

\section{Anna Barnett reports on the recent dip in projects entering the UN emissions offsetting programme.}

\section{A} UN programme supporting clean technology projects in the developing world is beginning to shrink as global economic woes and political uncertainty take their toll, say researchers. Set up as part of the Kyoto Protocol, the Clean Development Mechanism (CDM) lets developed countries buy credits assigned to emissions-reducing efforts in poorer nations in lieu of cutting greenhouse gases at home. The number of projects entering the CDM's approval process has recently started to slide. On average, 112 projects per month were submitted from November 2008 to January 2009, below the 2008 monthly average of 130 . Slumps this size have occurred before, but February had only 75 new projects submitted, a low not seen since 2006, when CDM activity was just starting to pick up (Fig. 1). And because projects often go through a lengthy period of development before seeking approval, "we may well see a further drop in the data in the next months" in response to the financial crisis, says Glenn Hodes, a senior economist with the UN Environment Programme Risoe Centre at the Technical University of Denmark in Roskilde.

Fewer projects mean less CDM-driven emissions cuts. In March analysts at the Risoe Centre lowered their estimate of total greenhouse gas emissions likely to be offset by the CDM during the period 2008-2012. In response to the dip in projects entering the scheme, they shaved 2 per cent, or 33 million Certified Emissions Reduction credits (CERs) - each representing greenhouse gas emissions equivalent to one tonne of $\mathrm{CO}_{2}$ - off their previous month's estimate ${ }^{1}$. Similarly, at the market research firm Point Carbon, the estimated pool of CERs for 2008-2012 has shrunk by 6 per cent, or 110 million tonnes of $\mathrm{CO}_{2}$, since January.

In a 2009 poll of carbon market investors by Point Carbon, 60 per cent said they had scaled down, delayed or cancelled investments in carbon credit projects because of the economic downturn. This includes projects undertaken in developed

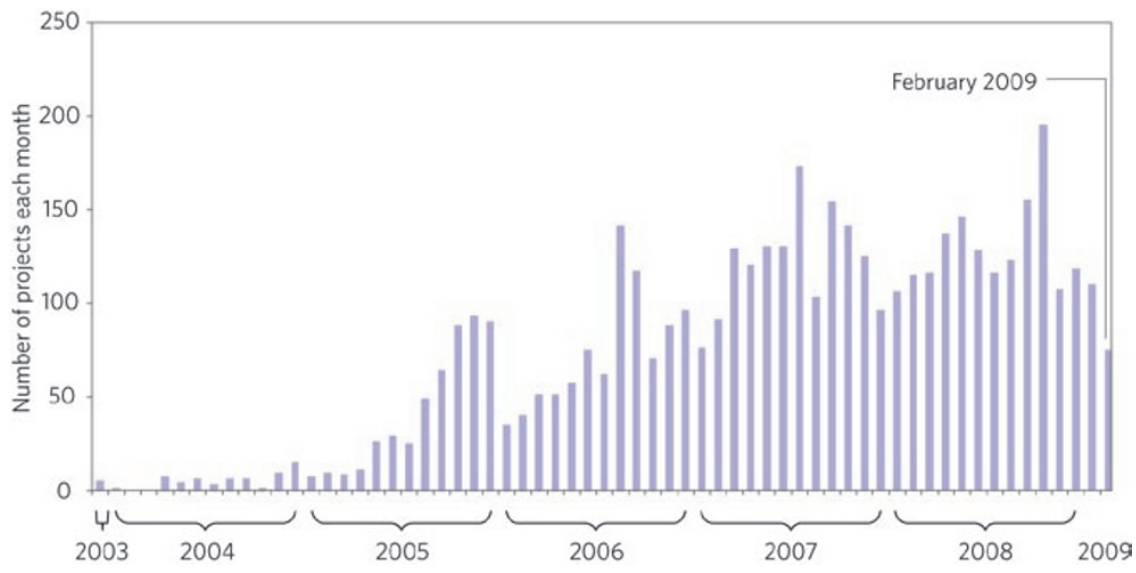

Figure 1 Number of CDM projects starting the evaluation process each month. Adapted from UNEP Risoe CDM/JI Pipeline Analysis and Database, March 1st 2009 (ref. 1).

countries, under a Kyoto mechanism known as Joint Implementation, as well as CDM ventures. In addition to difficulty obtaining loans in the current economy, CDM project backers have suffered a steep decline in the value of credits. At their nadir in mid-February, benchmark CERs traded at a quarter of their early-September price. Analysts say demand has dropped because the recession is hitting industry, damping down European emissions - and some cash-strapped companies are selling off their EU allowances, the credits they hold as part of the European carbon-trading scheme.

But the fall-off in new CDM projects would have happened without the financial crisis, says Arne Eik, an analyst at Point Carbon. "We're getting closer and closer to 2012," he says, referring to the date when a new global climate treaty, being negotiated in Copenhagen this December, will take effect. The deal is intended to replace the Kyoto Protocol, but until it's struck, the future role of the CDM - and revenues from its projects - can't be guaranteed. "If we get some good signals for the CDM in Copenhagen, I would expect it to increase again in spite of the difficult economic times," says Eik.
Others also expect the trend will soon turn around. Many of the companies most active in the CDM market anticipate an infusion of funds before the end of the year, according to the Point Carbon poll. Of those sampled, 46 per cent of CDM investors predicted they would increase their project investments in 2009, compared with 23 per cent who said investments would decrease or cease. A shift in US politics may be behind the optimism, says Eik, with President Obama pushing a national emissions cap and aiming for agreement in Copenhagen. These are good omens for carbon-cutting projects, he adds, even if those projects end up being part of a whole new framework. "It's not necessarily going to be the CDM as we know it," he says.

Published online: 16 April 2009

doi:10.1038/climate.2009.36

References

1. Fenhann, J., Agger, K. \& Hansen, U. E. UNEP Risoe CDM/JI Pipeline Analysis and Database (UNEP Risoe Centre on Energy, Climate and Sustainable Development, Roskilde, Denmark, 1 March 2009); http://cdmpipeline.org/index.htm

Anna Barnett is assistant editor and copy editor of Nature Reports Climate Change. 